\title{
Induction of lactational estrus in organic piglet production
}

\author{
A.G. Kongsted *, J.E. Hermansen \\ Department of Agroecology and Environment, Faculty of Agricultural Sciences, Aarhus University, Tjele, Denmark \\ Received 19 May 2009; received in revised form 6 July 2009; accepted 12 July 2009
}

\begin{abstract}
The longer lactation period required in organic piglet producing herds reduces the potential number of produced litters per sow per year compared with that of conventional production. Induction and use of lactational estrus may be a way to increase the productivity in organic production. However, if lactational estrus is to be beneficial under practical husbandry conditions, it is crucial that the majority of sows are successfully mated within a few days to make batch farrowing procedures possible. The objective of this study was to investigate the occurrence and timing of lactational estrus in an organic outdoor system based on ad libitum feeding, individual housing until Day 35 in lactation, followed by grouping and introduction of a boar and weaning of piglets after 8 wk. Five groups with four sows ((Danish Yorkshire $\times$ Danish Landrace) $\times$ Danish Duroc) in each were observed, and rank was determined by a food competition test. All sows showed lactational estrus, and $84 \%$ of these sows showed estrus within $1 \mathrm{wk}$, on average $43.5 \mathrm{~d}$ and $7.3 \mathrm{~d}$ after farrowing and boar introduction, respectively. The number of days from boar introduction to estrus increased significantly with increasing feed competition rank (the lowest number being the top rank position). Eighty-four percent of all sows were diagnosed pregnant $5 \mathrm{wk}$ after estrus. Behavioral observations revealed that the average total number of copulations per estrus sow was 2.3 with a range of 0 to 5 copulations. The findings of the current study indicate that it is possible to combine lactational estrus and batch farrowing procedures to increase the number of weaned piglets per year per sow in organic piglet production based on $8 \mathrm{wk}$ of lactation or more.
\end{abstract}

(C) 2009 Elsevier Inc. All rights reserved.

Keywords: Lactational estrus; Mating behavior; Organic; Pig production; Reproduction

\section{Introduction}

Organic piglet production is characterized by lesser productivity in terms of weaned piglets per sow per year compared with that of conventional piglet production. This is partly due to the longer lactation period required in organic production. According to European Union legislation, piglets may not be weaned until $40 \mathrm{~d}$ of age, and specific Danish and Swedish regulations stipulate a minimum lactation period of $49 \mathrm{~d}$. The longer lactation period

\footnotetext{
* Corresponding author. Tel.: +45 8999 1252; fax: +45 89991200.

E-mail address: AnneG.Kongsted[a]agrsci.dk (A.G. Kongsted).
}

has a direct effect on productivity because it reduces the potential number of produced litters per sow per year. The effect may, however, also be more indirect in terms of longer and unsynchronized weaning-toestrus intervals caused by ovulations during the last weeks of lactation $[1,2]$. As a consequence, lactational estrus is traditionally considered as disadvantageous in organic pig production in, for example, Denmark [3] and Sweden [1]. However, if it is possible to breed sows during lactation, this will not only increase sow productivity but also allow for delaying weaning beyond 40 or $49 \mathrm{~d}$ of age without jeopardizing sow productivity. Under seminatural conditions, the weaning is not completed before Week 13 [4] to 17 weeks [5] postpartum. An increased 
weaning age would thus comply well with the important aim in organic livestock production of allowing the animals to express their natural behavior. It would probably also reduce the risk of weaning diarrhea [6], which is a common problem in organic production [7].

If lactational estrus is to be beneficial under practical husbandry conditions, it is important that the majority of sows are successfully mated within a few days in lactation to make batch farrowing procedures possible. In an English on-farm survey, all sows showed lactational estrus on average $35 \mathrm{~d}$ after farrowing [8]. Approximately $70 \%$ of all the sows showed estrus within the same week, and $85 \%$ of these became pregnant. The sows were grouped about 3 wk post partum, fed ad libitum, and introduced to a boar $1 \mathrm{~d}$ after grouping. The accommodation used consisted of covered yards provided with an insulated lying area. Similar or less successful results have been obtained in other studies with indoor-housed sows [9].

We hypothesize that it is possible to obtain a more precise timing of lactational estrus in an organic sow herd by using grouping and boar introduction, due to the more stimulating environment in a system based on free-range production. Enriching the physical environment (e.g., more space, outside yards) has previously been shown to increase the occurrence of lactational estrus in sows [10].

In addition to group-housing, lactations lasting longer than $45 \mathrm{~d}$, and ad libitum feeding, frequent contact with a boar has been suggested as an important feature in inducing lactational estrus in sows [9]. It therefore seems obvious to combine the induction of lactational estrus in organic piglet production with unsupervised services by a boar within a group of sows. This system further complies well with the organic ideal of facilitating natural animal behavior. Unsupervised services in a group of lactating sows may, however, result in greater return rates as previously reported by Rowlinson and Bryant [11]. This may be caused by an uneven ratio of services per sow as suggested by Rowlinson et al. [8] and previously observed in outdoor multi-sire mating systems [11].

The objectives of the current experiment were to investigate (1) the occurrence and timing of lactational estrus in an outdoor system based on ad libitum feeding and individual housing from farrowing until Day 35 followed by grouping and the introduction of a boar; and (2) the reproductive behavior of sows and boars in a system based on induction of lactational estrus and unsupervised services by a boar within the group of sows.

\section{Materials and methods}

The study was conducted on a research station in the Middle of Jutland, Denmark. Five groups consisting of four multiparous sows per group were monitored from October 2006 to March 2007. The parity number varied from 2 to 11. All 20 sows were crossbreeds ((Danish Yorkshire $\times$ Danish Landrace) $\times$ Danish Duroc).

Two weeks before farrowing, the sows were moved from large pregnancy paddocks to individual farrowing/ lactation paddocks of about $500 \mathrm{~m}^{2}$. Each sow and her litter had access to a farrowing hut of approximately $3.5 \mathrm{~m}^{2}$. At farrowing, the number of dead and live-born piglets was recorded for each sow. Five weeks after farrowing, the four sows and their piglets were grouped (fences between the individual paddocks were removed). To allow individual identification during behavioral observations, the sows were sprayed with a color code on their backs. Two days after grouping, a boar was introduced (Day 0). An additional hut was placed in the paddock for the boar. The same two boars were used for all five groups. From Day 5 to Day 9, a "new" boar was introduced daily. The piglets were weaned at 7 to $8 \mathrm{wk}$ of age, and litters were weighed.

An organic complete pellet feed for lactating sows was given semi-ad libitum throughout the lactation period. The feed was given in individual troughs once daily. The food ration was gradually increased after farrowing. If there was feed left in troughs, the amount of feed allocated was slightly reduced at the next feeding. The feed contained 13.2 mega joule metabolizable energy (MJ ME) per kg feed and $15.5 \%$ crude protein. The boars were fed the same feed as the sows but were separated during feeding from the sows in a small enclosure in the corner of the paddock to avoid obesity. After grouping, the piglets had access to creep feed in a small enclosure in a corner of the paddock to which the sows had no access.

One sow from Group 1 had to be replaced soon after farrowing due to illness. She was replaced by a sow from the same farrowing batch in the herd. Another sow from Group 4 was excluded from the experiment due to mammary gland atrophy just after grouping. This sow only had four piglets at grouping, and they were in poor condition.

\subsection{Rank determination, occurrence of estrus, behavioral observations, and udder examination}

The ranking in each group was determined by performing a food competition test modified according to Andersen et al. [12]. The test was performed $2 \mathrm{~d}$ after grouping before boar introduction. A small amount of 
feed was placed on the ground in one corner of the paddock. The sow first claiming access to the feed was given rank 1 . Immediately after the determination of rank 1, a similar amount of feed was placed in another corner of the paddock, and the second rank was given to the sow that failed to displace rank 1 but succeeded in displacing the others. This continued until the rank of all four sows in the group had been determined.

Behavioral observations took place Day 3 to Day 10. The observations began at sunrise and continued to sunset ( 8 to $10 \mathrm{~h}$ of observation). However, if no estrusrelated activity had been observed in the morning at Day 3 or Day 4, the observations stopped at noon. Each time a boar courted a sow for more than $5 \mathrm{sec}$, the following information was recorded: boar ID, sow ID, time of start of courtship, behavior, and, if the courtship was terminated due to another sow, the ID of the terminator. The behaviors observed were classified into eight categories as described by Kongsted and Hermansen [13]: showing interest, standing reaction, mounting, copulation, sow walks away, boar walks away, another sow intervened, the sow collapsed. Copulation was defined as disrupted if the cause of termination was "the sow walked away," "another sow intervened," and "the sow collapsed." If intromission took place, the duration of the copulation was also recorded. The sows were checked for signs of estrus each day during the observation period by experienced technicians. The occurrence of estrus was defined by one or more of the following: observed standing reaction, observed mating, and swelling and coloration of the vulva.

The number of wounds on teats and udder as well as the number of milk-producing mammary glands was counted on the day of weaning by a research technician. All wounds were recorded and categorized into superficial scratches or more profound wounds.

\subsection{Back fat measurements and pregnancy diagnosis}

The back fat depth was measured on the sows $2 \mathrm{wk}$ before expected farrowing and at weaning by means of the digital ultrasound back fat indicator LEAN MEATER (Baltic Korn A/S, Naestved, Denmark). The back fat was measured $65 \mathrm{~mm}$ from either side of the spinal column at the 10th and 12th ribs, and all three layers of fat were measured. A total of four measurements were taken (two at each rib). The average value of the four measurements was used to characterize the back fat of the sow. One sow from Group 1 had to be replaced soon after farrowing. She was replaced by a sow from the same farrowing batch in the herd. Due to the late arrival, there is no information on the back fat at farrowing for this sow. One sow from Group 4 stopped lactating just after grouping but stayed in the group. The back fat at weaning of this sow was excluded from the data. At weaning litter weights were recorded.

Approximately $4 \mathrm{wk}$ after the end of the observation period, the sows were tested for pregnancy with an ultrasonic pregnancy diagnosis scanner (Agroscan A, EuroVet Aps Denmark).

\subsection{Statistical analyses}

The effect of rank order on the start of estrus was investigated by the following model:

$\mathrm{E}\left(\mathrm{Y}_{i k}\right)=\mu+\alpha_{i}+A_{k}$,

where $\mathrm{E}\left(\mathrm{Y}_{\mathrm{ik}}\right)$ is the expected number of days from boar introduction to estrus; $\mu$ is the general intercept; $\alpha_{\mathrm{i}}$ is the effect of rank ( $\mathrm{i}=1,2,3,4 ; 1=$ highest rank), and $A_{k}$ is the normally distributed random effects of group $(\mathrm{k}=1,2,3,4,5)$.

Due to correlations between parity, feed provided before grouping, back fat at weaning, back fat change in lactation, and the number of weaned piglets per litter, the effect of these variables was analyzed one by one by the following model:

$\mathrm{E}\left(\mathrm{Y}_{i k}\right)=\mu+v^{\bullet} y_{i k}+A_{k}$,

where $E\left(Y_{i k}\right)$ and $A_{k}$ are the same as in Equation (1), $y_{i k}$ is the effect of parity, feed provided before grouping, back fat at weaning, back fat change in lactation, and the number of weaned piglets, respectively, and $v$ is the corresponding regression parameter.

One sow was excluded from the above-mentioned analyses due to late estrus ( $17 \mathrm{~d}$ after boar introduction). The statistical analyses were performed with a linear mixed model using the MIXED procedure [14] in SAS [15]. PROC UNIVARIATE in SAS was used to test normality of the residuals.

\section{Results}

\subsection{Reproduction performance and behavior}

Timing of boar introduction and the reproduction performances of the five groups are shown in Table 1. Sixteen sows showed signs of estrus during the observation period, that is, from Day 3 to Day 10 after boar introduction. By coincidence, one lactating sow was observed mated by a boar after the observation period, $17 \mathrm{~d}$ after boar introduction. Two sows farrowed 110 and $111 \mathrm{~d}$ after weaning, respectively, indicating 


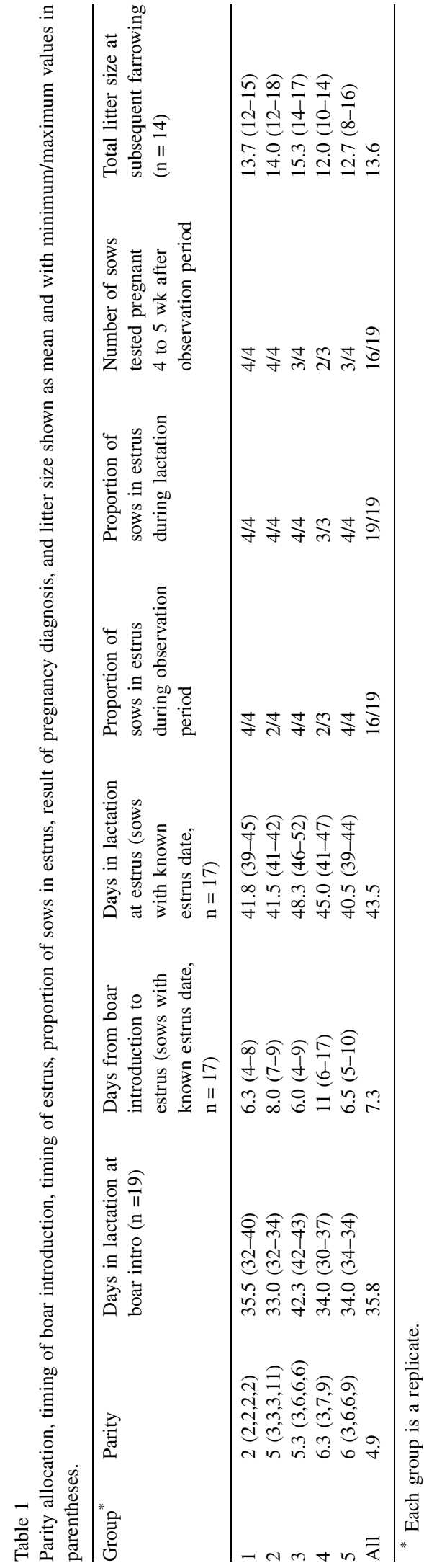

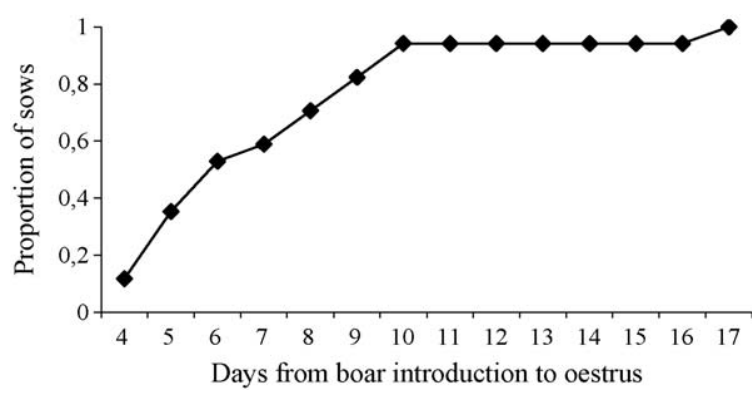

Fig. 1. Cumulative proportion curve for the interval between boar introduction and estrus.

that the pregnancy was established in the lactation but after the observation period. This means that all sows showed signs of lactational estrus, and $84 \%$ of these (16 of 19 sows) showed estrus within $1 \mathrm{wk}$. On average, the boar was introduced after an average of $35.8 \mathrm{~d}$ of lactation varying from 30 to $43 \mathrm{~d}$, and the sows showed signs of estrus 43.5 and $7.3 \mathrm{~d}$ after farrowing and boar introduction, respectively. There was no significant effect of group on days from boar introduction to estrus $\left(\sigma_{\text {group }}^{2}=0.6^{2}\right)$.

The cumulative proportion curve for the length of time from boar introduction to estrus for the 17 sows with known estrus date is presented in Fig. 1. Of the 19 sows showing lactational estrus, 16 had a positive pregnancy diagnosis. Two of these sows lost their pregnancies later on and returned to estrus. The remaining 14 sows had a mean litter size of 13.6 total born piglets at the subsequent farrowing as presented in Table 1.

The behavioral observations showed that of the three sows in estrus with a negative pregnancy diagnosis, only one sow had no observed mating. The other two sows had one and three observed copulations, respectively. The mean total number of copulations per estrus sow was 2.3 with a range of 1.5 to 3.0 between the five groups as shown in Table 2. Of all copulations, $26 \%$ lasted for $3 \mathrm{~min}$ or more. The frequency distribution for the total number of copulations per estrus sow is shown in Fig. 2. One of the two estrus sows with no observed copulations had a positive pregnancy diagnosis, so she must have had an unobserved mating. The total number of copulations per boar was 9 and 28, respectively. It was clear that the two boars differed in willingness to court and attempt intromission.

\subsection{Back fat changes, feed provision, litter performances, and udder examination}

The feed provided, back fat lost during lactation, and litter performances for the five groups are shown in 
Table 2

The total number of copulations per estrus sow (divided according to duration) for each of the five groups.

\begin{tabular}{|c|c|c|c|c|c|c|}
\hline Group* & $0-1 \mathrm{~min}$ & $1-2 \mathrm{~min}$ & $2-3 \mathrm{~min}$ & $3-5 \mathrm{~min}$ & $>5 \mathrm{~min}$ & Total \\
\hline 1 & 0 & 0 & $2 / 4$ & $7 / 4$ & $1 / 4$ & $10 / 4=2.5$ \\
\hline 2 & 0 & $1 / 2$ & 0 & $1 / 2$ & $2 / 2$ & $4 / 2=2.0$ \\
\hline 3 & 0 & 0 & $1 / 4$ & $3 / 4$ & $8 / 4$ & $12 / 4=3.0$ \\
\hline 4 & $1 / 2$ & 0 & 0 & $1 / 2$ & $1 / 2$ & $3 / 2=1.5$ \\
\hline 5 & $1 / 4$ & 0 & $3 / 4$ & $2 / 4$ & $2 / 4$ & $8 / 4=2.0$ \\
\hline All & $2 / 16$ & $1 / 16$ & $6 / 16$ & $14 / 16$ & $14 / 16$ & $37 / 16=2.3$ \\
\hline
\end{tabular}

* Each group is a replicate.

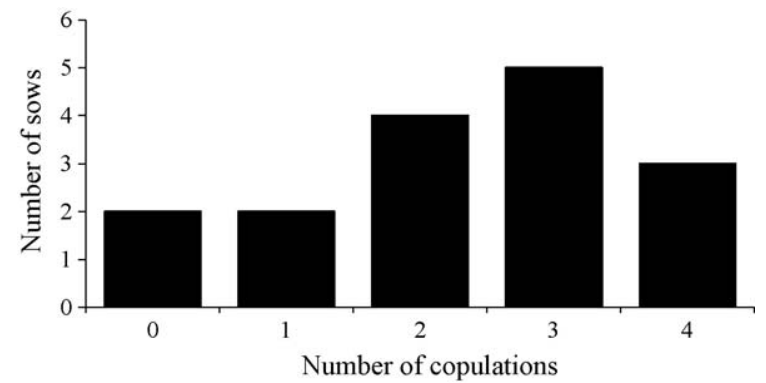

Fig. 2. The frequency distribution for the total number of observed copulations per sow in estrus during the observation period (one of the sows with no observed copulation had a positive pregnancy diagnosis).

Table 3. Between groups, the back fat thickness at weaning ranged from $8.3 \mathrm{~mm}$ to $15.7 \mathrm{~mm}$. Across groups, back fat change during lactation varied from a loss of $6.3 \mathrm{~mm}$ to a gain of $5.3 \mathrm{~mm}$ for the 19 sows. On average, the sows lost $1.1 \mathrm{~mm}$ back fat, corresponding with a reduction in back fat thickness of $9 \%$. The average amount of feed provided per sow per day increased from $128 \mathrm{MJ} \mathrm{ME}$ before grouping to $158 \mathrm{MJ}$ ME after grouping.

The examinations of the udders revealed that none of the 19 weaned sows had stopped lactating, and all sows had a matching number or additional milk-producing glands compared with the number of weaned piglets.
Fourteen sows had superficial wounds on the teats or udder but only 2.4 superficial wounds on average in the range 0 to 10 . Two sows had one and two more profound wounds, respectively, on the udder.

\subsection{Effect of rank order, parity group, back fat variables, feed provided, and number of weaned piglets on days from boar introduction to estrus}

The number of days from boar introduction to estrus was significantly affected by sow feed competition rank order (ls-means $=5.1,5.3,6.7$, and 10.0 for rank 1, 2, 3, and 4, respectively). There were no significant effects of parity $(a=-0.1)$ or any of the back fat variables (back fat at weaning: $\mathrm{a}=-0.05$; back fat loss: $\mathrm{a}=-0.08)$, the amount of feed provided before grouping $(a=-0.01)$, or the number of weaned piglets $(\mathrm{a}=-0.1)$ on the timing of estrus.

\section{Discussion}

We hypothesized that it would be possible to obtain a better timing of lactational estrus in an organic outdoor sow herd than previously found in conventional indoor sow herds using the same stimulating factors in terms of grouping followed by boar introduction. In the current study, all sows showed signs of lactational estrus

Table 3

Feed provided, back fat data, and litter performance shown as mean and with minimum/maximum values in parentheses.

\begin{tabular}{|c|c|c|c|c|c|c|c|c|}
\hline Group $^{*}$ & $\begin{array}{l}\text { Feed provided } \\
\text { before grouping, } \\
\text { MJ ME } \\
\text { sow }^{-1} \mathrm{~d}^{-1} \\
(\mathrm{n}=20)\end{array}$ & $\begin{array}{l}\text { Feed provided } \\
\text { after grouping, } \\
\text { MJ ME } \\
\text { sow }{ }^{-1} \mathrm{~d}^{-1} \\
(\mathrm{n}=20)\end{array}$ & $\begin{array}{l}\text { Back fat at } \\
\text { weaning, } \\
\text { mm }(n=19)\end{array}$ & $\begin{array}{l}\text { Back fat gain in } \\
\text { lactation, } \mathrm{mm} \\
(\mathrm{n}=18)\end{array}$ & $\begin{array}{l}\text { Back fat gain } \\
\text { in lactation, } \% \\
(\mathrm{n}=18)\end{array}$ & $\begin{array}{l}\text { Weaning age } \\
(\mathrm{n}=19)\end{array}$ & $\begin{array}{l}\text { Number of } \\
\text { weaned pigs } \\
\text { per sow } \\
(\mathrm{n}=19)\end{array}$ & $\begin{array}{l}\text { Weight at } \\
\text { weaning, } \\
\mathrm{kg} / \text { piglet } \\
(\mathrm{n}=185)\end{array}$ \\
\hline 1 & $114(107-118)$ & 156 & $8.3(6-10)$ & $-1.8(-3 \rightarrow-0.5)$ & $-18(-33 \rightarrow-5)$ & $55.5(52-60)$ & $11.5(10-13)$ & 17.0 \\
\hline 2 & $135(133-137)$ & 168 & $9.9(7.8-14.3)$ & $-2.1(-4.8 \rightarrow-0.5)$ & $-17(-37 \rightarrow-5)$ & $53.0(52-54)$ & $11.3(9-13)$ & 15.8 \\
\hline 3 & $130(127-132)$ & 161 & $10.4(8.5-14.5)$ & $-1.1(-2.3 \rightarrow-0.5)$ & $-10(-19 \rightarrow-5)$ & $56.3(56-57)$ & $9.8(8-11)$ & 19.5 \\
\hline 4 & $122(119-126)$ & 138 & $15.7(13.8-19)$ & $+2.2(-1.8 \rightarrow+5.3)$ & $-22(-11 \rightarrow 5.8)$ & $53.0(49-56)$ & $5.7(4-9)$ & 13.3 \\
\hline 5 & $141(141-142)$ & 168 & $13.1(7.8-21.5)$ & $-2.2(-6.3 \rightarrow 0)$ & $-15(-45 \rightarrow 0)$ & $55.0(55-55)$ & $9.5(7-11)$ & 17.4 \\
\hline All & 128 & 158 & 11.3 & -1.1 & -9 & 54.6 & 9.7 & 16.6 \\
\hline
\end{tabular}

* Each group is a replicate. 
between Days 34 and 52 after farrowing, and 84\% of the sows exhibited estrus within a period of $1 \mathrm{wk}$, from Day 4 to Day 10 after boar introduction. This is an improvement in the timing compared with that of previous reports (e.g., [8,16-18]), and it promises well for the future use of lactational estrus in practical organic piglet production to improve productivity.

The pregnancy rate of $84 \% 4$ to $5 \mathrm{wk}$ after estrus is greater than previously reported [16] but comparable with another study [8] based on induction of estrus during lactation and unsupervised services by a boar. The result is slightly less than the farrowing rates reported in organic [19] and conventional [20] sow herds mainly using artificial insemination. The behavioral observations revealed that most of the sows showed behavioral estrus but that the two boars differed in willingness to court and attempt intromission. Large individual differences in sexual behavior in boars are also reported and discussed by Kongsted and Hermansen [13] and by Rowlinson and Bryant [21]. It seems very likely that conception rates can be improved if more effort is put into evaluating the sexual behavior of boars before using them in a system such as this. The total number of observed copulations per estrus sow was 2.3 , varying from 1.5 copulations in Group 4 to 3.0 copulations per sow in Group 3. The sexual activity in Group 4 was generally less than that in the other groups. This is probably due to very low temperatures in combination with frozen ground at the time of boar introduction. The animals found it very difficult to walk on the frozen, uneven surface. This might have impaired their motivation for sexual activity. Avoiding this type of surface in paddocks used for natural mating is therefore important, especially during winter.

There seems to be no adverse effect of lactational estrus on litter performance $[8,16]$, unless copulation occurs very early after farrowing [17]. The average piglet weight at weaning varied from $13 \mathrm{~kg}$ to $20 \mathrm{~kg}$ per pig at group level after $55 \mathrm{~d}$ of lactation in the current study. This is comparable with previous reports based on corresponding weaning ages and servings after weaning $[22,23]$.

The current experiment was conducted on sows farrowing from October to January. The autumn and early winter period has previously been associated with a greater proportion of sows showing lactational estrus compared with, for example, summer months $[2,3,16,24]$ and is also coincident with the breeding season of the wild sow in Northern Europe [25]. Further large-scale studies that include all seasons are required to provide a more complete understanding of the perspectives in the use of lactational estrus in organic piglet production.
A large feed intake in lactation has been suggested as crucial for induction of lactational estrus [9]. In this study, the average feed intake before grouping was 128 MJ ME per day corresponding with approximately $10 \mathrm{~kg}$ feed per day for the first $5 \mathrm{wk}$ in lactation. This is greater compared with sow feed intake reported in other studies on indoor housed lactating sows with corresponding lactation periods of 4 [26] to $6 \mathrm{wk}$ [27] and may be a contributing factor to the high proportion of sows showing lactational estrus in the current study. The experimental sows were (Danish Landrace $\times$ Danish Yorkshire) $\times$ Duroc crossbreeds. Crosses with Duroc are known for a greater appetite during lactation [28] and greater back fat at weaning [19] compared with that of Landrace $\times$ Yorkshire crosses.

Sow feed competition rank affected days from boar introduction to estrus significantly. The number of days increased with increasing rank (the least number being the top rank position). Field observations of wild pigs (Sus scrofa) also suggest a synchronization of estrus within the family herd with the leading sow initializing estrus for the whole group [25]. Similar relations have been observed in groups of goats, where the highranking goats were the first to have ovulations and to conceive [29]. The mechanisms behind the effect of rank are not known, but the authors suggest that it is caused by a more intense stimulation of the dominating female as a result of closer association to the males. In the current study, however, there were no indications that high-ranked sows were more involved in overall sexual activity than were lower-ranked sows.

The findings of the current study indicate that it may be possible to combine lactational estrus and batch-wise farrowing procedures to increase the number of weaned piglets per year per sow in organic sow herds. This may pave the way for an organic pig production based on even longer lactation periods than the currently stipulated 6 to $7 \mathrm{wk}$. It has been speculated that a long lactation period may compromise the welfare of the sow due to large weight losses. However, a recent study showed that it is possible to increase lactation length to $10 \mathrm{wk}$ under practical husbandry conditions without jeopardizing the welfare of the sows [19]. An increased weaning age closer to "nature" does not only comply better with the principles of organic livestock production [30] but also seems to have a positive impact on the productivity of the piglets. Results from a pilot study where induction of lactational estrus was combined with a prolonged weaning age revealed that a weaning age of $11 \mathrm{wk}$ compared with 8 wk increased piglet daily gain by $60 \%$ to $80 \%$ from Week 8 to Week 15 in an organic sow herd (A.G. Kongsted, unpublished data, 2006). 


\section{Acknowledgments}

The authors wish to thank the research technicians Orla Nielsen and Kristine Riis Hansen for their much appreciated assistance in carrying out the data collection. We would also like to thank the employees at the research station, Rugballegård, for taking good care of the animals.

\section{References}

[1] Rydhmer L, Wallenbeck A, Hultén F. Reproduction and maternal behaviour in organic piglet production. In: NJF-seminar 369, Organic farming for a new millennium - status and future challenges, vol. 1. Nordic Association of Agricultural Scientists (NJF), Section I: Soil, Water and Environment, Swedish University of Agricultural Sciences, Alnarp, Sweden, 15-17 June; 2005, pp. 207-210.

[2] Hultén F, Wallenbeck A, Rydhmer L. Ovarian activity and oestrous signs among group-housed, lactating sows: influence of behaviour, environment and production. Reprod Domest Anim 2006;41:448-54.

[3] Kongsted AG, Hermansen JE. Laktationsbrunst i økologiske sohold-et gode eller et onde? Forskningsnyt 2005;4:26-8.

[4] Newberry RC, Wood-Gush DGM. The suckling behaviour of domestic pigs in seminatural environment. Behavior 1985;95: $11-25$.

[5] Jensen P, Recén B. When to wean-observations from freeranging pigs. Appl Anim Behav Sci 1989;23:49-60.

[6] Jensen P, Stangel G. Behaviour of piglets during weaning in a seminatural enclosure. Appl Anim Behav Sci 1992;33: 227-38.

[7] Bonde MK, Sørensen JT. Animal health and welfare in organic European pig production: State of the art and challenges for the future, based on a Northwestern European questionnaire survey. In: Organic Farming and European Rural Development: Proceedings of the European Joint Organic Congress. Danish Research Centre for Organic Food and Farming; 2006p. 562-3.

[8] Rowlinson P, Boughton HG, Bryant MJ. Mating of sows during lactation: observations from a commercial unit. Anim Prod $1975 ; 21: 233-41$

[9] Alonso-Spilsbury M, Mayagoitia L, Trujillo ME, RamirezNecoechea R, Mota-Rojas D. Lactational estrus in sows, a way to increase the number of farrowings per sow per year. $\mathrm{J}$ Anim Vet Adv 2004;3(5):294-305.

[10] Henderson R, Stolba A. Incidence of estrus and oestrous trends in lactating sows housed in different social and physical environments. Appl Anim Behav Sci 1989;22:235-44.

[11] Rowlinson P, Bryant MJ. Lactational oestrus in the sow. 3 The influence of feeding level upon the occurrence of a fertile oestrus in lactating sows Anim Prod 1982;35:49-53.

[12] Andersen IL, Bøe KE, Kristiansen AL. The influence of different feeding arrangements and food type on competition at feeding in pregnant sows. Appl Anim Behav Sci 1999;65:91-140.
[13] Kongsted AG, Hermansen JE. The mating behaviour and reproduction performance in a multi-sire mating system for pigs. Theriogenology 2008;69:1139-47.

[14] Littell RC, Milliken GA, Stroup WE, Wolfinger RD. SAS ${ }^{\circledR}$ System for Mixed Models. SAS Institute Inc., $633 \mathrm{pp}$.

[15] SAS Institute Inc. SAS/STAT ${ }^{\mathbb{R}}$ User's Guide. SAS Institute Inc., 1990.

[16] Petchey AM, Jolly GM. Sow service in lactation: an analysis of data from one herd. Anim Prod 1979;29:183-91.

[17] Rowlinson P, Bryant MJ. Lactational oestrus in the sow. 1. The effect of the interval between farrowing and grouping on the incidence and timing of lactational oestrus in sows. Anim Prod 1981;32:315-23.

[18] Wechsler B. Rearing pigs in species-specific family groups. Anim Welfare 1996;5:25-35.

[19] Kongsted AG, Hermansen JE. Sow body condition at weaning and reproduction results in organic piglet production. Acta Agri Scand A Anim Sci 2009;59:93-103.

[20] Jultved CR. Rapport over P-rapporternes resultater oktober 2006. Dansk Svineproduktion, notat nr. 0627, 2006.

[21] Rowlinson P, Bryant MJ. Lactational oestrus in the sow. 2. The influence of group-housing, boar presence and feeding level upon the occurrence of oestrus in lactating sows. Anim Prod 1982;34:283-90.

[22] Lauritsen HB, Sørensen GS, Larsen VA. Organic pig production in Denmark. In: Ecological Animal Husbandry in the Nordic Countries, Hermansen JE, Lund V, Thuen E (Eds.), DARCOF Report 2, 2000, Danish Research Centre for Organic Farming, pp. 113-118.

[23] Edge H, Breuer K, Hillman K, Morgan C, Stewart A, Strachan D, et al. Agewean-the effect of weaning age on growing pig health and performance in the absence of antibiotic growth promoters. Proc Br Soc Anim Sci 2008;10.

[24] Hultén F, Lundeheim N, Dalin A-M, Einarsson S. Reproductive performance among sows group-housed during late lactation. Acta Vet Scand 1998;39:237-50.

[25] Meynhardt H. Schwarzwild-report. Mein leben unter wildschweinen. Neumann Verlag 1990;221 pp.

[26] Danielsen V. Fodringsstrategier for diegivende søer. I, Jakobsen K, Danielsen V (Eds.), Optimal fording af søer. DJFrapport 2006, 75, Danish Institute of Agricultural Sciences, pp. 26-28.

[27] Hultén F, Lundeheim N, Dalin A-M, Einarsson S. Pre- and postweaning piglet performance, sow food intake and change in backfat thickness in a group-housing system for lactating sows. Acta Vet Scand 1997;38:119-33.

[28] Heyer A, Andersson K, Leufven S, Rydhmer L, Lundström K. The effects of breed cross on performance and meat quality of once-bred gilts in a seasonal outdoor rearing system. Arch Tierz Dummerstorf 2005;48:359-71.

[29] Alvarez L, Martin GB, Galindo F, Zarco LA. Social dominance of female goats affects their response to the mail effect. Appl Anim Behav Sci 2003;84:119-26.

[30] DARCOF. Principles of Organic Farmining. Discussion document prepared for the DARCOF Users Committee. Danish Research Centre for Organic Farming, 2000, 34 pp. 